\title{
Religious Identity and Identity Diffusion in Romantic Relationships: Exploring Married Women in Inter-Religious Context of India
}

\author{
Damini Vyas ${ }^{1 *}$
}

\section{ABSTRACT}

Identity is the most widely studied concept in the field of psychology and sociology. The concept of identity has many variables contributing to its formation such as social, culture, religion etc. Religion plays important roles when it comes to determining the identity of the individual holistically. Since childhood an exposure to a particular religion helps the individual form their religious identity thus when the individual is introduced to a culture and practices of another religion they can experience confusion or diffusion. When women are married into another religion they are more likely to be exposed to the cultural and religious practices of their spousal family's religion thus they can experience identity diffusion. James Marcia explained the concept of identity diffusion as a hallmark of lack of commitment, basically it is the confusion experienced by the individual within their religious identity when exposed to another religion. This study aims to understand the religious identity of women of inter-religious marriages in India. The study also aims at understanding whether the exposure of a new religious culture and practices has caused diffusion in their identity. It is an explorative qualitative research design which uses thematic analysis to study the responses of 6 females who have engaged into interreligious marriage.

Keywords: Religious Identity, Identity Diffusion, Inter-Religious Marriages \& Females

"Anyone who thinks sitting in church can make you a Christian must also think that sitting in a garage can make you a car.”-Garrison Keillor

The individuals who get into an alliance of marriage have to adjust with each other for years to come, however if there is an inclusion of religion or culture into these set of adjustments then that adds one more dimension to the process of developing a strong bond between the couple. Based on the data collected by pew forum on religion and public life, 37\% of the American citizens have engaged in marital alliance with someone from a different religion. While

\footnotetext{
${ }^{1}$ Research Scholar, Dept. of Psychology, Christ University, Mumbai, India

*Responding Author

(C) 2016 D Vyas; licensee IJIP. This is an Open Access Research distributed under the terms of the Creative Commons Attribution License (http://creativecommons.org/licenses/by/2.0), which permits unrestricted use, distribution, and reproduction in any Medium, provided the original work is properly cited.
} 


\section{Religious Identity and Identity Diffusion in Romantic Relationships: Exploring Married Women in Inter-Religious Context of India}

According to "Dynamics of Inter-religious and Inter-caste Marriages in India", which used data taken from the 2005-2006 "National Family Health Survey of 42,183 people in 29 states, 2. 1 percent of marriages in India were inter-religious (Das, Tripathy, Das \& Roy, 2015).”

In an Indian society the religion plays a very vital role in the development of the individual and his/her identity. Most of the people born in this society tend to swear by the roles expected out them by their religion and experience distress or discomfort when they do not fulfil their roles (Canada Immigrant and refugee world, 2012) Thus both the partners have to ponder upon their dedications towards their faith and decide whether this is a very important factor which will affect and have an influence on their future relationship or will it not (Harris, 2012). If the religion does play a major role in their lives then it may be a root cause for several major arguments and disagreements in the future (e. g. the faith of the child). If the religion doesn't play any importance to the couple, then they will have same amount of issues like those who share the same denomination of religion. Inter religious marriages are marriages that involve individuals who follow two different religions (e. g. Hindu-Muslim, Muslim-Christian, HinduChristian etc.) (Gross,1991) According to Lawlor inter-religious marriages have 50\% more chances of failure and divorce than same religion marriages.

Thus based on the above mentioned studies and findings there has been a link between religion and identity formation within individual. Also there are many issues within the inter-religious marriage setting.

\section{Issues within inter-religious marriage}

A few issues that couples with diverse religions need to manage are, for instance, fluctuated religious practices, religious convictions and laws, family issues, premature birth, anticonception medication, manual sperm injection, nourishment readiness, sexual forbearance, the head or force of a marriage, settling on choices including their youngsters, and some more. In the event that the individual or his/her accomplice is not eager to concentrate on the same confidence, then resistance of diverse qualities and religions, duty, and obligation is vital in this sort of marriage; else, it is truly hard to seek after this relationship in light of the fact that managing distinctive purposes of perspectives and convictions is a major stride in a married couple's life (Ho, 2004)

One of the principle clashes brought by the birth of a child within the marriage. There are circumstances where a few with diverse religions have children who haven't built up their religious identity, however when that minute comes, a mutual decision needs to be made about the child's religious identity. The child will be included between two distinct religions and the parents will be the ones accountable for examining and contending about it (Harris, 2012). Religious Identity 


\section{Religious Identity and Identity Diffusion in Romantic Relationships: Exploring Married Women in Inter-Religious Context of India}

Religion is one domain in which people tend to undergo patterns of change, both between childhood and adulthood and across the adult lifespan, but little is known about the influence of religion on development of identity. For many, religion is an important factor in formation of social identity and association with religious groups are among the most basic and central sources of social identity. There are evidences which state that an individual's stronger mental health is strongly affected by his/her social identities especially the religious identity, and their expectations about their religious group. However, religious identity can also be quite complex, because of the complexity of religion itself. The hierarchy that is a part of many religious institutions can cause the complexities in the formation of the identity (Greenfield \& Marks, 2007).

Moreover, religion includes not only identifying with the group but also the individual's overt and covert behaviours and how much do they actually believe in what they do. "The relative importance of these elements varies between religions and cultures contributing to even greater complexity of identities" (A. B. Cohen, 2009) individuals have different level of social identities based on their level and dedication towards the group, beliefs of religion and actually performing the roles expected out of them. Some may only identify with the religion without actually Similarly, one may perform activities - like prayer or meditation—or hold a set of beliefs that one perceives as religious, without identifying with a particular religious’ organization.

Such individuals might be described and see themselves as part of the category "religious person," and continue to derive positive social identity from their religion through identification with this relatively abstract group. Because religious behaviour has generally been found to follow a nonlinear trajectory over the life course, being relatively high through early adolescence, then dropping off precipitously before beginning an increase again in middle adulthood that continues into old age these multiple forms may make it easier for individuals to maintain a sense of temporal congruence in their religiousness. That is, one can continue to think of oneself as "religious, "based on category identification or beliefs, even when one is not actively participating in religious activities (Levin and Taylor, 1997).

This study aims to view at the probability of religious identity of the individual with the help of Erik Erickson's psychosocial model. As this model is the best model to study the connections of the sub-themes emerging from the research and also the connecting points in the field of research.

\section{Rationale}

Religion has a major role in development of individual's identity which is seen in findings by Oppong (2013). This research studies the relation of religion and identity from the Durkheim's insight and the formation of identity and the ethnicity of the individual. In an Indian society, 


\section{Religious Identity and Identity Diffusion in Romantic Relationships: Exploring Married Women in Inter-Religious Context of India}

religion is a major factor in determining the individual on a whole there have been no relevant researches conducted in this area and thus the current study aims at studying the religious identity in an Indian context.

Religion also plays a fundamental role in an individual's decision of marriage and thus has a foremost influence on it. Mainly the society is against the decision of marrying an individual from another religion or caste which is seen in study by Pue \& Sulaiman (2013). Where the findings reveal that not only relatives and other family members are against it, even government bureaucrats create issues with couples who have been married in different religion or are planning on doing so.

This is seen in even in the Indian context in the study by Das, Das, Roy \& Tripathy, (2011). The findings of this study reveal that only 2. $1 \%$ of the population have engaged in inter-religious marriages. Thus the current study aims to study this population and also the religious identity of this population.

\section{METHODOLOGY}

Using convenient sampling technique 6 participants were interviewed using a semi-structured interview. They were given the freedom to choose their place of comfort and after a rapport session of 30 minutes the main interview was conducted. The interview conducted was to fulfil the objectives of the study which are: (i) To understand the existences of religious identity of married females in inter-religious marriages.

(ii) To study the possibility of identity diffusion within religious identity if exposed to another culture and practices.

A consent form was given at the beginning of the interview.

\section{RESULTS AND DISCUSSION}

The findings presented are on the basis of the analytical typologies: (i) Acceptance and (ii) conviction vs. confusion. The verbatim quotes from the participants are based on the commonalities found amongst their responses.

Table 1

Global theme Organising theme Basic theme

Acceptance. Intra-personal Acceptance of -Acceptance of the apprehension. new religious practices.

Societal Acceptance

Spousal family acceptance for decision of no conversion

- Denial of the Apprehension.

-Based on religion.

-Based on age and skin complexion.

-No issues with the decision.

-Supported (not asking to convert)

-Didn’t support (asked to convert) 
Religious Identity and Identity Diffusion in Romantic Relationships: Exploring Married Women in Inter-Religious Context of India

Offspring's religion

Acceptance of offspring's marriage in other religion. Spousal family acceptance in the family.
-Personal decision

-Offspring's choice

-Husband's decision

-- Acceptance of all religions.

- Acceptance of certain religions.

-Acceptance of the individual over religion.

-Acceptance of the traditions and culture.

\section{Acceptance.}

The theme acceptance in the study has many factors contributing to it each factor has been analysed and explored to give it a common one factor the following themes contribute together to form the major theme of decision making.

\subsection{Intra-personal Acceptance.}

When enquired about their decision of getting married into another religion even after years of marriage there was a mixed reaction. Out of the 6 participants interviewed, 2 of them agreed that they still do think about their decision of getting married in another religion. Here are their responses.

"yes, as living here is different than back home, also their ways are so different than ours like for example every Sunday we have to go to church while back home for us it was never a compulsion (to go to the temple) so it didn't matter. " (p.p.3, personal communication, 21december, 2015)

"yes, there are times where I feel left out in certain family rituals. I do think I wish I had married in my own religion. ” (p.p.5, personal communication, 28 december, 2015)

Here, their thought of marrying into another religion are based on their experiences of being a part of certain rituals that they haven't been raised to during childhood eg going to church. Every once a week while the participant's maiden family didn't have the compulsion to visit a temple once a week. However in the case of the second participant the reason for wishing to marry into her own religion were the rituals where she mentioned that she felt left out and that led to giving a thought of her decision of marrying in another religion.

\subsection{Social group Acceptance.}

Marriages in India aren't just between two individuals but between two families and thus apart from the couple the extended family also needs to approve of the institution. The participant had varied answers. 


\section{Religious Identity and Identity Diffusion in Romantic Relationships: Exploring Married Women in Inter-Religious Context of India}

\subsubsection{Issue based on age and skin colour}

One of the participant responded that family on the spousal side had an issue with her skin colour and the family on her side had an issue with the age difference between her husband and her, they thought that they aren't matured enough to decide about marriage following is the excerpt of her interview.

"the was only one I mean as of now will do the rituals and the second thing was I am a little dark. Parent's side was that he is younger to me so we are not matured enough and your and his thinking is different which I couldn't see at that particular point and then they knew he is a good person.” (p.p.5, personal communication, 28 December, 2015)

\subsubsection{Issue based on religiosity}

There were two participants whose families had an issue with their decision of marrying into another religion one of them mentioned that her family thought that she was committing a sin by marrying into another religion but there were few who supported her decision too.

"There were definitely mixed reaction. mistake while some bucked me up" communication, 21 december,2015)

The other participant mentioned that there was an issue however since there were inter-religious marriages in her family so they knew about the rituals and cultures of the in-laws however the concern was eating habit since the in-laws were vegetarian.

"Yes, there were a little issue but then there are many of my aunts who have married into Hinduism so it didn't really bother much. My mom however had certain concerns about how I will adjust with the family and all. Also my in-laws are vegetarian so the issue was of that since I had been eating meat since childhood and now this." (p.p.4, personal communication, 26 December, 2015)

\subsubsection{No issues with the decision}

There was a participant whose family didn't have an issue with her decision of marrying into another religion.

"Not that I can recall or know of." (p.p.2, personal communication, 27 December, 2015)

\subsection{Spousal family acceptance on the decision of not converting.}

Almost all the participants mentioned that their spousal family was supportive of their decision of not changing their religion except one participant's family based on another person who agreed on converting however her decision of not converting was strongly supported by her husband the following excerpt is from her interview

(c) The International Journal of Indian Psychology, ISSN 2348-5396 (e)| ISSN: 2349-3429 (p) | 194 


\section{Religious Identity and Identity Diffusion in Romantic Relationships: Exploring Married Women in Inter-Religious Context of India}

"Yes they did ask for conversion but my husband was very strong if she wants her take this decision doesn't force if she wants let her do anything. In-laws still feeling that I should convert because my husband's little brother also married a Hindu and they made sure that she gets converted and she converted so when they see that they insist why don't you do that so that we have a universal religion at home and there won't be any confusion."(p.p.6, personal communication, 19 December, 2015)

\subsection{Decision of children's religion.}

The major question that is first raised when spoken about inter-religious marriage is which religious the children shall follow.

\subsubsection{Personal decision}

Most of the participants decided to baptise their child based on their personal decision which they had decided before marriage the following are the excerpts from their interview.

"Both my children, now aged 27yrs and 25 yrs were baptised when they turned 18, a personal decision by them, and totally supported by their father and me." (p.p.2, personal communication, 27 December, 2015)

"Taught about both religions even after being baptised but they decided on Christianity it's their choice because they are grown up and they have always been close to Christ its gods plans for them." (p.p.6, personal communication, 19 December, 2015)

"I said I need to baptised the child and they had to give in and I said he is here with prayers and even when we got married we had to sign a petition that all your kids will be catholics so they gave in because it happened according to me." (p.p.5, personal communication, 28 December, 2015)

"Currently I am planning on getting at least one of my child baptised." (p.p.3, personal communication, 21 December, 2015)

\subsubsection{Decision depends on the husband.}

One of the participant mentioned that she left the decision of her children's religion on her husband. However currently she has left the decision on her children and if they can't decide she will leave let the husband decide she said she is comfortable with either.

"It's up to them. They now say I am half Christian and half Hindu but somewhere they have to decide. First of all, I won't enforce anything on them if they are not able to decide at all then I will give the chance to my husband. So let him decide as I said I am not all strict if he says let

(c) The International Journal of Indian Psychology, ISSN 2348-5396 (e)| ISSN: 2349-3429 (p) | 195 


\section{Religious Identity and Identity Diffusion in Romantic Relationships: Exploring Married Women in Inter-Religious Context of India}

them be Christian I am fine and if he says let them be Hindu I am fine.” (p.p.1, personal communication, 22 December, 2015)

\subsubsection{Based on the children.}

One of the participants has decided to let her child decide their religion when they feel so and currently she is inculcating the values of both the religions to her child.

"I would like my kids to follow both the Hindu and the Christian religion. I believe no religion is bad. When he/she is an adult, they would be free to choose what values to carry forward." (p.p.4, personal communication, 26 December, 2015)

\subsection{Acceptance of offspring's marriage in another religion.}

When questioned about their acceptance of their offspring's wish to marry someone in another religion apart from the one they have married in and the one they are following the responses varied in terms of acceptance of a third religion.

\subsubsection{Acceptance of all the religions.}

Three out of the six participants interviewed said that they would support their offspring if s/he decides to marry into a third religion the following are their responses.

"Yes. But only if the other family is as liberal and open minded as mine was." (p.p.2, personal communication, 27 December, 2015)

"Yes. Why not I've married in another religion why should stop my son from doing so? And honestly the family nowadays are really open minded and liberals so it doesn't matter. I think religion is just namesake." (p.p.3, personal communication, 21 December, 2015)

"Yes. Definitely I would. I would love to have people of different cultures as a part of my family.” (p.p.4, personal communication, 26 December, 2015)

\subsubsection{Acceptance of only few religions.}

The other three participants said that they wouldn't have an issue if their child married in another religion but they did have an issue with certain religion as that is another ritual and practice altogether.

"If I were to decide I wouldn't want any new religion in the family as that would only create new issues.” (p.p.1, personal communication, 22 December, 2015) 


\section{Religious Identity and Identity Diffusion in Romantic Relationships: Exploring Married Women in Inter-Religious Context of India}

"Apart from a few religion yes I will be okay." (p.p.5, personal communication, 28 December, 2015)

"Another religion now what would say more from here. Ya I was just talking to him please don't get married to a Muslim it's not like I have anything against them its basically how you conduct yourself and I face so many issues I don't want him to face so many issues.” (p.p.6,personal communication, 19 December, 2015)

\subsection{Spousal family acceptance post marriage.}

Since all of the participants have engaged in love marriage they were asked about their acceptance in the spousal family after marriage. The acceptance was based on two factors

\subsubsection{Acceptance based on the individual}

One of the participant mentioned that she was accepted by her individuality and the way her mother in law supported her during her initial time of marriage.

"I didn't know cooking and my mother in aw taught me cooking and making rot is the exact size she's very loving like that they never made an issue of me not having kids they didn't have any that thoughts but somewhere deep down they did have those things that somewhere if they had a better choice they would have chosen her that was there" (p.p.5, personal communication, 28 December, 2015)

\subsubsection{Acceptance of traditions and values}

The rest of the participants mentioned that they consider their acceptance based on the traditions and values of conduct and the manner the spousal family engaged in the rituals.

"They never objected to me continuing with my religion for instance my parents house we celebrate ganpati and get an idol home for 5 days and during those days they allowed me to fast and also visit them, they even accompanied me one day and accepted the prasad and all which made me feel really happy and nice. Even my mom who had doubts was assured that this wasn't a mistake” (p.p.3, personal communication, 21 December, 2015)

"My wedding was conducted with Hindu rituals. My in-laws participated in everything with true heart and without questioning us if they had an option to not participate. This made me even more confident that I will be able to keep my religious values." (p.p.4, personal communication, 26 December, 2015)

"Since they never asked me to convert that says it all that they are supportive towards my decision. And in terms of the rituals and all, all they ask me is to be there and pray if I want and

(c) The International Journal of Indian Psychology, ISSN 2348-5396 (e)| ISSN: 2349-3429 (p) | 197 


\section{Religious Identity and Identity Diffusion in Romantic Relationships: Exploring Married Women in Inter-Religious Context of India}

I do go to the temples and say my own prayers as after all god is one, these are just different names for the person's own convenience. And sometimes simple rituals they tell me how to do also that is if I want to do them. There is no force or anything." (p.p.5, personal communication, 28 December, 2015)

"I had lot of support from my own parents who are very devoted Catholics their prayers were very strong and I had only one bro in law who was like a kid to me so it was strong so we need had any issue we are a small family. We celebrated both diwali and Christmas and even had veg and non veg sat together and ate food together." (p.p.6, personal communication, 19 December, 2015)

"Not instances in every aspect they are supporting they never force or bring any fight they never I mean separate me its they who are coming forward an supporting, my delivery my mother in law my two deliveries my mother in law took care, when I was ill she came when I met with an accident she came to look after me. When I had to go abroad she came to look after the kids, then I had to write an exam she came to look after the kids so complete support from that side despite umm knowing that I am not of their religion and knowing that I am not yet plan to umm convert.” (p.p.1, personal communication, 22 December, 2015)

The second major theme that emerged from the data is conviction v/s confusion. As the individual proceeded in the marital life with introduction of the new religion the cultural practices and rituals created a personal conviction and confusion within themselves.

Table 2

Global theme

Conviction v/s Confusion

practices and family.

Conversion.

Personal conviction

Adjustment issues

Second thoughts about marriage.

\author{
Organising theme \\ Indulgence in religious \\ practice. \\ Conflict against religious \\ confirmation.

\section{Basic theme} \\ -General practices. \\ -Against their ideologies. \\ -No. \\ -Yes. \\ Balance of religious -Family not religious. \\ -Festivities celebrations. \\ -thought about it \\ -havent thought about it. \\ -Maintenance. \\ -Consideration. \\ -Based on convictions. \\ - Agreed
}

-Disagreed

(c) The International Journal of Indian Psychology, ISSN 2348-5396 (e) | ISSN: 2349-3429 (p) | 198 


\section{Religious Identity and Identity Diffusion in Romantic Relationships: Exploring Married Women in Inter-Religious Context of India}

\section{Conviction vs Confusion}

The second theme that emerged from the data is conviction vs confusion here the participants has an influence of their childhood parental upbringing in determining their religious identities. The sub themes that formed the category of the global theme are mentioned in the following:

\subsection{Indulgences in other religious practices and rituals.}

The reaction for this statement was a complete mixed as few have mentioned that they have participated in these religious practices and some have mentioned they haven't.

\subsubsection{General practices.}

The participants those who have participated in the religious rituals of the spousal family mention that the ritual conducted by them wasn't a very important or very significant in matte and thus they did it. The following are the excerpts from their interview.

"Sat for a mass and also fasted during their period of length. I respect all religions, so it was no big deal. But it was awkward with the not going out for shopping and watching movies during the length period.” (p.p.3, personal communication, 21 December, 2015)

"Yea, yes, every Christmas we celebrate every Easter we celebrate actually more than my husband I am more I do more Christian celebration so I insist on visiting church and I insist on umm somewhere at least let us be art of some group or church because it will other effects kids can have better school and their other cultural activities can be enhanced like if they are in a choir or singing this kind of orientation they can have more if we are in this kind of group but as of now we have are very neutral. Yes I do participate and all.” (p.p.5, personal communication, 28 December, 2015)

"Not the major ones. But general ones like puja during diwali, at first it felt weird but then we light candles instead of diyas so it doesn't really make a difference.” (p.p.4, personal communication, 26 December, 2015)

One response that stood out was of the participant who mentioned that her participating in the ritual was a distressing to her due to difference of customs and she mentioned that she felt horrible about the custom here is her response to the question.

"I remember it one incident when there was a puja in my relative's house and I was down with periods that time I went and did the puja part and when they came to know they looked down on me and then I was made to sit separate even while eating food I was asked to sit separately which was really odd for me. One incident that time that made feel really bad was so during the puja they were just giving Ice cream and you know my masi as in mother-in-law's sister instead 
Religious Identity and Identity Diffusion in Romantic Relationships: Exploring Married Women in Inter-Religious Context of India

of giving it to me in my hand she slid it down to me so that I can eat it and I felt horrible about it you know" (p.p.6, personal communication, 19 December, 2015)

\subsubsection{Practices against their religious ideologies.}

When asked about their participation in any customs or traditions that belong to their spousal family's religion but are against their own religious ideologies most of the participants denied in indulgences in these practices. The following are their responses.

"No I have not he has never asked me. I sit next to him when he prays and vice versa." (p.p.1, personal communication, 22 December, 2015)

"Not in a negative way like ummm....... i don't know in baptism of my niece we were supposed to be the godfather and mother since I wasn't a Christian I couldn't participate in it." (p.p.6,personal communication, 19 december,2015)

“No I haven't I had decided to marry with this condition that I will not participate in religious acts as I don't know what they signify and without faith I don't want to hurt the sentiments of them" ( p.p.5, personal communication, 28 december,2015)

“No I haven’t.” (p.p.3, personal communication, 21 December, 2015)

"My religion says that I should bow before another god as own and I believe that. And most of our rituals are pretty much similar and neither of our festivals crash so it didn't really matter to me but Haven't yet participated in anything that's against my ideologies" (p.p.4,personal communication, 26 December, 2015)

\subsection{Conflict against religious confirmation.}

Religion does have an influence with the daily activities and customs also it does affect the mode conduct in terms of the traditions. Thus they were asked about whether religion has been an issue of conflict with their spouses.

\subsubsection{No it is not an issue of conflict.}

When asked the participants whether difference in religion has caused a conflict between them and their spouses most of them said no it hasn't been issue of conflict. the following are their excerpts.

"No, not really but once I participated in a puja when I was on my period which got my mom in law a bit annoyed but then she understood that I wasn't aware about this so she forgave me.

(c) The International Journal of Indian Psychology, ISSN 2348-5396 (e)| ISSN: 2349-3429 (p) | 200 


\section{Religious Identity and Identity Diffusion in Romantic Relationships: Exploring Married Women in Inter-Religious Context of India}

However with my husband we've never had such a fight.” (p.p.5, personal communication, 28 December, 2015)

"No religion has never been like that we have always had discussion," (p.p.1, personal communication, 22 December, 2015)

"Nothing to talk about. Even he accompanies me to temple at times." (p.p.2, personal communication, 27 December, 2015)

“Never. (I feel blessed to say so).” (p.p.3, personal communication, 21 December, 2015)

\subsubsection{Yes it has been an issue of conflict.}

Two of the participants have mentioned that yes there was a conflict between her and her spouse where the difference of religion has been the main topic. The reason for the conflict was the uncomforted with the traditions and family involvement. Here are the excerpts from their interview.

"Ya in the sense umm..see there are certain rituals which he is not comfortable specially Hindu related thing umm where umm when we go to temple we have to remove the shirt he is a little uncomfortable and have to remove the chappal and during my periods I have to stay of the temples theses all make him uncomfortable. And I am from the south, south kerela and we have a totally different culture wherein we pray to the spirits and that kind of and we have to give owing by animals which he is not at all comfortable though I don't personally do that but my family and relatives do that which he is not all comfortable which he prefers not to attend that makes me uncomfortable and I have to attend this creates a void there only in that circumstances."(p.p.6, personal communication, 19 December, 2015)

"Yes I mean I used to go to church everyday he slowly started objecting I mean he started keeping things the time I had to go to church and there were lot of issues and things were the second one came in and there were lot of issues happening I spend a lot of times with the kids so he felt neglected such thing started happening and then he stopped me from going to church and he wouldn't come first he used to come to the church also an I started feeling alone like then I used to take the kids then he would have objections with that and slowly the kids would also try their way out the younger one said you're a Christian you go and I am a Hindu and I will stay." (p.p.4, personal communication, 26 December, 2015)

\subsection{Balance of religious practices and family practices.}

When asked about their ways to strike a balance between their religious practice and the spousal family practices and tradition the participants mentioned that they maintain balance mainly

(c) The International Journal of Indian Psychology, ISSN 2348-5396 (e)| ISSN: 2349-3429 (p) | 201 


\section{Religious Identity and Identity Diffusion in Romantic Relationships: Exploring Married Women in Inter-Religious Context of India}

through the celebration of all the festivities, the spousal family itself isn't that religious and the she herself is balanced as a person.

"When we have mass in our house my in laws come and sit for it and when there's a puja I sit for that.” (p.p.1, personal communication, 22 December, 2015)

"Nothing to talk about. Even he accompanies me to temple at times" (p.p.4, personal communication, 26 December, 2015)

"I'm just myself when it comes to being a part of any religion. I gel well with my in laws as well as my maiden family so it's all celebrations and I enjoy that." (p.p.2, personal communication, 27 December, 2015)

"Well we celebrate both the religion's festival with equal enthusiasm and fun" (p.p.3, personal communication, 21 december,2015)

"My in laws are not religious so I have never been in such a situation but to maintain balance I sit and do rituals for both the religions so both the gods are happy." (p.p.5, personal communication, 28 December, 2015)

\subsection{Conversion}

When asked if they think it would've been better had they converted to their spouse's religion. Most of them refused the idea of it. The following are their responses.

“No. not yet.” (p.p.1, personal communication, 22 December, 2015)

"No I have never given that aspect I have always experienced god talking to me when I say heavenly father he says I am with you and that is my faith very strong god the father son holy spirit is with me." (p.p.2, personal communication, 27 December, 2015)

"Never. My religion gives me enough freedom to believe in another religion and still follow mine.” (p.p.3, personal communication, 21 December, 2015)

"I would like everybody to have independent thoughts and beliefs. No one should ever force any beliefs on anybody. And in the way that I would not follow anyone else's religion blindly, I cannot expect anyone else to follow mine.” (p.p.4, personal communication, 26 December, 2015)

“No not at all neither does he feel so." (p.p.5, personal communication, 28 December, 2015) 


\section{Religious Identity and Identity Diffusion in Romantic Relationships: Exploring Married Women in Inter-Religious Context of India}

However, one participant mentioned that she thinks she shouldn't have married to a person not from her own religion here is her response from her interview.

"In fact thought the other way I thought I should not have got married here and got married to someone from my religion." (p.p.6, personal communication, 19 December, 2015)

\subsection{Personal conviction.}

Personal conviction is based on two factors their consideration of being religious within the participants and their ways to maintain their religiosity and dynamics with their religious groups.

\subsubsection{Consideration}

All the participants agreed that they do consider themselves as a religious person and have a belief in God.

"Saying my prayers going for mass living a true Catholics following the commandments that god has given us.” (p.p.1, personal communication, 22 December, 2015)

“Yes I consider myself as Hindu.” (p.p.2, personal communication, 27 December, 2015)

"Faith and belief gives birth to a religion, this is my opinion. " (p.p.3, personal communication, 21 december,2015)

"Cannot define but its one's belief in a particular God and following certain teachings". (p.p.5, personal communication, 28 december,2015)

"My spirituality or religious is my connect with people and my connect with my own self and umm basically I feel very connected with my own self and threat is when I feel I am connected to god.” (p.p.6, personal communication, 19 december,2015)

"Yes yes yes, umm I have the umm background of Hinduism." (p.p.4, personal communication, 26 december,2015)

\section{5. 2 Maintenance of group dynamics}

The participants mentioned their ways to maintain their dynamics with their religious groups. "I do my daily puja and fast once in a while whenever there are festivals. Also celebrate them." (p.p.3, personal communication, 21 december,2015) 


\section{Religious Identity and Identity Diffusion in Romantic Relationships: Exploring Married Women in Inter-Religious Context of India}

"Yes, for what my family taught me when I was growing up, I still retain that. These include believing in Karma, not eating meat and loving all groups of human beings." (p.p.4, personal communication, 26 december,2015)

"I go to the church every Sunday and do my daily prayers which are what prescribed in my bible. What a true good catholic should do.” (p.p.1, personal communication, 22december,2015)

"Praying to Christ going to church every Sunday and following the commandments of Christ." (p.p.2, personal communication, 27 december,2015)

“That's what I don't relate myself with the group as such I maybe Hindu within myself and follow within myself, nothing specific if there is a festival then introducing the festival to the kids where they need to be aware I do and if I don't do there isn't something I feel I should be doing so I don't feel anything even if I cannot do, if I can do I will do." (p.p.5, personal communication, 28 december,2015)

\subsection{Adjustment issues.}

The adjustment issues post marriage was mainly family tradition based and their expectation based.

"No since I'm staying in a nuclear family. However, I did have issue with my extended family and rituals but now I am kind of learning everything as well.” (p.p.3, personal communication,21 december,2015)

"Yes though not difficult per se but I did take time to adjust to the food and smaller living place like though being a Maharashtrian we used to eat non-veg but that wasn't everyday but on certain days here we eat it everyday so it was difficult also the cooking style and the type of masalas etc. was different and back at my parents' house we were 4 people in 3-bedroom house and here the living space was smaller so it took time but no it all good." (p.p.2,personal communication, 27 december,2015)

"No I never had any problem my father in law was a very good man and members of the family were very good so I never had problem of going to church or anything an when they had their function I was the one who took care of everything for them." (p.p.1, personal communication, 22 december,2015)

"It was difficult for me to believe that my husband does not share any strict views towards his religion. He believes in God but not in any particular religion. Neither him nor is family very 


\section{Religious Identity and Identity Diffusion in Romantic Relationships: Exploring Married Women in Inter-Religious Context of India}

religious. However, they all respect other peoples' religions and that makes me proud of them." (p.p.3, personal communication, 21 december,2015)

"Ummm. not really one was I was open and second I did have an exposure of Christianity from my very childhood and umm third thing is that as I am not rigid I was ok I do conduct all the things that are there in Christianity and I do all the thing that are there in Hinduism so there's no conflict." (p.p.5, personal communication, 28 december,2015)

\subsection{Second thoughts about marriage.}

When asked the participants whether they did have any second thoughts about marrying in another religion they mentioned they yes did have those thoughts and their main worry as the adjustment with the family customs and tradition. However, those who said they didn't have any second thoughts they were more confident in their partner rather than the family altogether.

"Of course 2nd, 4th, 5th, 6th, $7^{\text {th }}$ so many thoughts. no I said no this one thing actually it was to satisfy my ego that I have chosen how I can fall in front of the society that you know he is not right choice that was the thing that I held no to at that particular time and I wasn't so aware also that this is not the reason to get married and there was no guidance see basically what we feel you have this rebelling attitude that I have done the right choice and correct person you don't go to the depth of the things of you need to relate to the person and understand the person so that time that awareness was not there and was there any prepatory course except for that when it came to this we realized we are different. "(p.p.1, personal communication,22 december,2015)

"Yes I did have second thoughts many times but then I realized that even when we were dating we had issues which we solved together by talking and its thru communication everything can be solved so I knew that my husband will understand me and support me." (p.p.2, personal communication, 27 december,2015)

"No. I was in this relationship for 8 years before marriage, so knew what I was in for. But then yes there were pre wedding jitters as being in a relationship is one thing and getting married is another thing. So I did think if it was worth it but then of my 8 years and I knew it will be alright.” (p.p.3, personal communication, 21 december,2015)

"No there were no second thoughts we both loved each other and we decided to get married" (p.p.4, personal communication, 26 december,2015)

"As in umm.. no I was very comfy with the person these things were not very significant in our lives it was a very secondary thing. So that's why we went ahead." (p.p.5, personal communication, 28 december,2015)

(c) The International Journal of Indian Psychology, ISSN 2348-5396 (e)| ISSN: 2349-3429 (p) | 205 


\section{Religious Identity and Identity Diffusion in Romantic Relationships: Exploring Married Women in Inter-Religious Context of India}

"No, we cleared our thoughts on our beliefs in religion. I am currently happily following my religion and hold all my religious values. My partner doesn't intervene between me, my god and my beliefs.” (p.p.6, personal communication, 19 december,2015)

\section{DISCUSSION}

"When the subject may or may not have experienced a period of crisis and has neither decided upon a religion nor is $\mathrm{s} / \mathrm{he}$ bothered about it but also shows a preferred inclination towards a particular religion in his/her daily routine and gives the impression that s/he is ready to give up if the opportunity arises, the person then is going through identity diffusion (Marcia, 1966)". Marcia developed the theory of identity statues where he divided the states of identity formation into four states viz. identity foreclosure identity diffusion, identity moratorium and identity achievement. These four states are the basic states an individual during adolescences goes through in order to achieve the in order to achieve a healthy psychological unity of self (Moulin,2013) .

In a multi-religious society like India the culture and society plays a vital role in identifying and formation of the religious identity (Das, Tripathi, Das \& Roy. 2015). thus the possibility of having a one particular religious is very less which is seen in the present data where the participants are females and have married into another religion.

The participants have shown a general acceptance of another religion however they still in certain forms maintain the religious identification with ones they were raised with during childhood. The formation of identity diffusion as a state was from Erik Erickson's ego-identity theory where he views the identity formation among adolescents with a psychosocial perspective. With the help of the same frameworks the author developed the questions for the interview where in the author aimed at exploring the acceptance of a new religious practices and culture within the participants of the study and their social group.

Based on the finding of the interview the participants were generally acceptant towards the religious practices of the spousal family however there was an apprehension about their decision of marrying into another religion due to factors like the spousal family acceptance when it comes to certain rituals and due to the difference in the way of living. This contributes to the factor of possible identity diffusion.

Apart from the apprehension within themselves the participants also mentioned they would have their children to follow the religion which they are currently following it portrays that they would have some part of their own childhood upbringing to contribute to their method of upbringing of children based on the definition of identity diffusion given by James Marcia a subject is not bothered by the decision of religion but does show an inclination towards it in their 


\section{Religious Identity and Identity Diffusion in Romantic Relationships: Exploring Married Women in Inter-Religious Context of India}

daily activities, the decision of most of the participants to get their offspring to follow their own religion shows an inclination of identity diffusion. Also when questioned about their acceptance of another religion if their child decides to marry into another religion most of the participants said that they would accept their child's decision thus based on the definition of identity diffusion the subject will give up the impression (of the formed identity) if something better arrives. Here the betterment is the happiness of the child and future of the child thus proving that there exist identity diffusion within married females when married into another religion.

Religion is one domain in which people tend to undergo patterns of change, both between childhood and adulthood and across the adult lifespan (Levin \& Taylor, 1997; Uecker, Regnerus, \& Vaaler, 2007), but little is known about the influence of religion on development of identity. For many, religion is an important factor in formation of social identity (Deaux, Reid, Mizrahi, \& Ethier, 1995), and association with religious groups are among the most basic and central sources of social identity (Lickel et al. , 2000; Turner, Hogg, Oakes, Reicher, \& Wetherell,1987). Religion includes not only identifying with the group but also the individual's overt and covert behaviours and how much do they actually believe in what they do. "The relative importance of these elements varies between religions and cultures contributing to even greater complexity of identities" (A. B. Cohen, 2002, 2009) individuals have different level of social identities based on their level and dedication towards the group, beliefs of religion and actually performing the roles expected out of them.

The data does show a strong sense of religious identification as they do not only consider themselves as a religious person but they also mention the various practices that they conduct during their daily activities. Their personal conviction talks about their identification with their religion. The biggest give away of their strong sense of identification of their religion comes from the refusal to convert or even think about converting to their spouse's religion. According to Levin \& Taylor, 1997 there are people identify with their religion on two different ways one is through their daily religious activities such as going to church or performing the morning puja etc, most of the participants in some or the other form do engage in these daily activities and the second category are those who need not require to do these activities in order to call themselves religious. Two of the participants of this study mentioned that they aren't a religious person but they do belong to a religion and consider the higher being above. All of this shows their socialization efforts to identify with a particular religion.

The covert behaviour of the participants also shows how they have a strong identification with a particular religion when the participants were questioned about their participation in rituals that are against their religious ideologies and teaching they all strongly refused about it. They also mentioned that they did have worries and jitters about the difference in religion and also the 


\section{Religious Identity and Identity Diffusion in Romantic Relationships: Exploring Married Women in Inter-Religious Context of India}

adjustment within the tradition and customs. Thus this shows that religion does have an influence on the individual's identity formation and there exist religious identity.

\section{CONCLUSION}

With the data and the analysis it shows that yes there exists a religious identity and religion does play a role in the formation of identity. When people are introduced to a new context and religion they hold on to their religion and they tend to have diffusion within their formed identity.

\section{LIMITATIONS}

The study is conducted on females who haven't converted and thus it is limited only to that population. There can be possibility that the identification with religion can still persist amongst females who have agreed on conversion for the sake of marriage. The sampling technique used was a convenient sampling and thus there can be a possibility of having socially desirable answers for certain sensitive questions.

\section{IMPLICATIONS OF THE STUDY}

This study will contribute in the research field of religious identity. It will also give a light to the compromise of identity that people who ignore their identity for the sake of love. With the help of this study one can learn to identify with their religious inclination and improve their interpersonal relationship with the spousal family as they will be better aware about themselves.

\section{Acknowledgments}

The author appreciates all those who participated in the study and helped to facilitate the research process.

\section{Conflict of Interests}

The author declared no conflict of interests.

\section{REFERENCES}

Hinduism:: Hindu Religion Religious India. Retrieved 4 January 2015, from http://www.123helpme.com/hinduism--view. asp? id=163155

Spirituality, Hinduism, Samsara (Reincarnation) and Karma. Retrieved 4 January 2015, from http://1stholistic.com/prayer/hindu/hol_hindu-samsara-and-karma.htm

Adams, G., \& Shea, J. (1979). The relationship between identity status, locus of control, and ego development. J Youth Adolescence, 8(1), 81-89. http://dx.doi.org/10.1007/bf02139142

Bell, D. (2009). RELIGIOUS IDENTITY Conceptualization and measurement of the religious self (Ph. D). Emory University. 


\section{Religious Identity and Identity Diffusion in Romantic Relationships: Exploring Married Women in Inter-Religious Context of India}

Bertramâ Troost, G., de Roos, S., \& Miedema, S. (2006). Religious identity development of adolescents in religious affiliated schools. A theoretical foundation for empirical research. Journal Of Beliefs \& Values, 27(3), 303-314.

doi:10. 1080/13617670601001165.

Bibikova, A. ,\& Kotelnikov, V. (2015). EASTERN versus WESTERN PHILOSOPHY Differences and Similarities. Cultural Intelligence, World Cultures comparison by Anastasia

Bibikova and Vadim Kotelnikov. 1000ventures. com. Retrieved 4 January 2015, from http://www.1000ventures.com/business_guide/crosscuttings/cultures_east-westphylosophy.html.

Boyatzis, R. (1998). Transforming qualitative information: Thematic analysis and code development. New Delhi: SAGE publications.

Braveman, J. (2013). The Human Life Cycle Stages Retrieved 4 January 2015, from http://www.livestrong.com/article/79177-human-life-cycle-stages/

Canada Immigrant and refugee world. (2012, may 11). http://www. refworld.org/docid/50b4a36c2. html. Retrieved July 4, 2015, from www. refworld. org: http://www.refworld. org/docid/50b4a36c2. html.

Cila, J. , \& Lalonde, R. (2013). Personal openness toward interfaith dating and marriage among Muslim young adults: The role of religiosity, cultural identity, and family connectedness. Group Processes \& Intergroup Relations, 17(3), 357-370. doi:10. 1177/1368430213502561.

Das, Kumadin, K. C. Das, T. K. Roy and P. K. Tripathy. [2011]. Dynamics of Inter-religious and Inter-caste Marriages in India. Paper prepared for 2011 annual meeting of the Population Association of America, Washington, DC, March 31-April 2, 2011.

Flood, G. (2015).BBC - Religions - Hinduism: History of Hinduism. Bbc.co.uk. Retrieved 4 January 2015, from

http://www.bbc.co.uk/religion/religions/hinduism/history/history_1.shtml

Fu, Xuanning, Jessika Tora, and Heather Hendall. 'Marital Happiness And Inter-Ra'. cialmarriage: a community study in multi-ethnic community in hawaii 32. 1 (2001): 4760. Print.

Ginsburg, S., \& Orlofsky, J. (1981). Ego identity status, ego development, and locus of control in college women. J Youth Adolescence, 10(4), 297-307.

http://dx.doi.org/10.1007/bf02088993.

Gupta, V. ,Surie, G. , Javidan, M. , \&Chhokar, J. (2002). Southern Asia cluster: where the old meets the new? Journal of World Business, 37(1), 16-27. doi:10. 1016/s10909516(01)00071-2

Harris, V., Marts, G. , \& Kumaran, M. (2013). Promoting Healthy Relationship Development in Teens, Part II: Three Key Qualities to Foster Better Relationships, University of Florida. 


\section{Religious Identity and Identity Diffusion in Romantic Relationships: Exploring Married Women in Inter-Religious Context of India}

Ho, S. (2015). Interfaith Marriage. Kean. edu. Retrieved 18 July 2015, from http://www.kean. edu/ eslprog/accents/2004/page2004_15. Html

Howard, J. 'Expecting And Accepting: The Temporal Ambiguity Of Recovery Identities'. Indiafamily.net,. (2015). India Family Main Menu. Retrieved 18 July 2015, from http://indiafamily.net/talk/messages/54/247. html?915058324

Jespersen, K., Kroger, J., \& Martinussen, M. (2013). Identity Status and Ego Development: A Meta-Analysis. Identity, 13(3), 228-241.

http://dx.doi.org/10.1080/15283488.2013.799433

Josselson, R. (1987). Finding herself. San Francisco: Jossey-Bass.

Lopez, A., Huynh, V., \& Fuligni, A. (2011). A Longitudinal Study of Religious Identity and Participation During Adolescence. Child Development, 82(4), 1297-1309. http://dx.doi.org/10.1111/j.1467-8624.2011.01609.x

Marcia, J. (1966). Development and validation of ego-identity status. Journal of Personality And Social Psychology, 3(5), 551-558. http://dx.doi.org/10.1037/h0023281

Misra, S. (2007). Spirituality, Culture and the Politics of Environmentalism in India. Journal Of Entrepreneurship, 16(2), 131-145. doi:10. 1177/097135570701600201

Peek, L. (2005). Becoming Muslim: The Development of a Religious Identity. Sociology Of Religion,66(3), 215. http://dx.doi.org/10.2307/4153097

Prasad, M. (2004).Philosophical and cultural perspectives on acoustics in Vedic Hinduism. J. Acoust. Soc. Am., 115(5), 2528. doi:10.1121/1.4783372

Refugees, U. (2015). Refworld | India: Situation of inter-religious couples from bothurban and rural locations, including societal attitudes, treatment by government authorities and the treatment of their children (2005-April 2012). Refworld. Retrieved 25 July 2015, from http://www.refwoRita. M. Gross. (1991). RELIGIOUSDIVERSITY: Some Implications for Monotheism. University of Wisconsin-Eau Clairrld. org/docid/50b4a36c2. Html

Rowe, I., \& Marcia, J. (1980). Ego identity status, formal operations, and moral development. J Youth Adolescence, 9(2), 87-99. http://dx.doi.org/10.1007/bf02087928

Schwartz, A. (2015). The Emotional Challenges of Interfaith Marriage. Psych Central.com. Retrieved 18 July 2015, from http://psychcentral.com/lib/the-emotional-challenges-ofinterfaith-marriage.

Shoveller, J., Johnson, J., Langille, D., \& Mitchell, T. (2004). Socio-cultural influences on young people's sexual development. Social Science \& Medicine, 59(3), 473-487. doi:10. 1016/j. socscimed.2003. 11. 017

Willig, C. (2001). Introducing qualitative philadephia: Open University Press.

Youniss, J., McLellan, J., \& Yates, M. (1999). Religion, community service, and identity in American youth. Journal Of Adolescence, 22(2), 243-253.

http://dx.doi.org/10.1006/jado.1999.0214

How to cite this article: D Vyas (2016), Religious Identity and Identity Diffusion in Romantic Relationships: Exploring Married Women in Inter-Religious Context of India, International Journal of Indian Psychology, Volume 3, Issue 4, No. 74, ISSN:2348-5396 (e), ISSN:2349-3429 (p), DIP:18.01.040/20160304, ISBN:978-1-365-46362-4

(c) The International Journal of Indian Psychology, ISSN 2348-5396 (e) | ISSN: 2349-3429 (p) | 210 